\title{
Fatigue Behavior and Life Prediction Model of a Nickel-Base Superalloy under Different Strain Conditions
}

\author{
Peng Zhang ${ }^{1}$, Qiang Zhu ${ }^{1}$, Gang Chen ${ }^{1}$, Heyong Qin ${ }^{2}$ and Chuanjie Wang ${ }^{1, *}$ \\ ${ }^{1}$ School of Materials Science and Engineering, Harbin Institute of Technology at Weihai, Weihai 264209, China \\ ${ }^{2}$ Central Iron \& Steel Research Institute, Beijing 100081, China
}

\begin{abstract}
The fatigue behavior of a nickel-base superalloy was investigated under total strain-controlled mode at high temperature. The fatigue life, cyclic stress response behavior and hysteresis loop of the superalloy were investigated under isothermal low cycle fatigue (LCF) conditions. The superalloy exhibited cyclic hardening and softening behaviors during the process of fatigue loading. The hysteresis loop shifted downwards slightly with the increase of the number of cycles. The fatigue life under different strain amplitudes reflects the interactions of dislocations and $\gamma^{\prime}$ precipitates at elevated temperature. Three life prediction models to evaluate the fatigue life of the superalloy were evaluated for the LCF tests. The prediction values obtained by Manson-Coffin relationship agree well with the experimental results. The mechanisms of LCF were revealed through the observation of the microstructures by scanning electron microscopy (SEM) and transmission electron microscopy (TEM). The main deformation mechanism of the superalloy is the different interactions between dislocations and $\gamma^{\prime}$ precipitates. [doi:10.2320/matertrans.M2015316]
\end{abstract}

(Received August 5, 2015; Accepted October 6, 2015; Published November 13, 2015)

Keywords: nickel-base superalloy, low cycle fatigue, cyclic stress response behavior, fatigue life model, fracture mechanism

\section{Introduction}

With the rapid development of the aeronautics career, further improvement of the thrust-weight ratio is highly required in the development of aero-engines. The improvement of the thrust-weight ratio puts forward higher requirements for hot-end components of new-type turbine disks. Turbine disks must possess perfect resistance to mechanical cyclic loadings so as to withstand the superposition of centrifugal loadings and thermal stresses during takeoff and landing processes. ${ }^{1)}$ Nickel-based superalloys possess high temperature strength, high temperature oxidation resistance, hot corrosion resistance, fatigue resistance, persistent strength and creep resistance at elevated temperature, which can adapt to the reliable working requirements under harsh conditions such as high temperature and strong corrosion. ${ }^{2,3)}$ Nickelbased superalloys have become the key engineering materials for turbine disks in gas turbines and aeroengines due to their excellent high temperature performance. Turbine disks are subjected to the combined effects of mechanical stresses and high temperature in the service condition. ${ }^{4,5)}$ In this case, LCF damage easily occurs for turbine disks, which reduce the service life and affect the normal use of turbine disks. Cyclic deformation and the accumulation of fatigue damage in nickel-base superalloys depend on microstructure and deformation modes under testing conditions. ${ }^{6}$ Fatigue damage and crack initiation occur primarily due to the accumulation of irreversibly slipping dislocations in nickelbase superalloys with a limited content of metallurgical defects. ${ }^{7)}$ Most nickel-base superalloys have a complex microstructure, including inhomogeneously distributed precipitates, a distribution of grain size, and varying grain boundary character. Under cyclic fatigue loading, inhomogeneous microstructure may act as either sources of dislocations or local stress concentrators, contributing to cyclic strain localization. ${ }^{8)}$ At low temperature, precipitate shearing is the

*Corresponding author, E-mail: cjwang@hitwh.edu.cn dominant deformation mode in nickel-base superalloys since thermally activated dislocation processes are inhibited at low temperature. ${ }^{9,10)}$ At high temperature, the combined effects of precipitate shearing and bypass are the dominant deformation mode in nickel-base superalloys. ${ }^{11)}$ The various hot-end components experience periods of fluctuating mechanical and thermal stresses due to the complex changes in stress and temperature during service environments. Hence, more recently, high temperature low cycle fatigue has attracted growing intention for scholars and researchers to understand more realistic alloy behaviors. A large number of investigations focused on the effects of strain rate, strain range, grain refinement, orientation, hot corrosion and testing temperature on fatigue behaviors of nickel-base superalloys. ${ }^{12-19)}$ Shyam et al. ${ }^{12)}$ investigated the effect of loading parameters on fatigue fracture surface morphology in a nickel-base superalloy. Lu et al. ${ }^{13)}$ studied the effect of hold time on low cycle fatigue behavior of HAYNES $230^{\circledR}$ superalloy at elevated temperatures. Bhattacharyya et al. ${ }^{14)}$ investigated the effect of microtwinning orientation on low cycle fatigue of Inconel 718 at low strains. Marchionmi et al. ${ }^{15)}$ investigated high temperature LCF behavior of UDIMET $720 \mathrm{Li}$ superalloy. Goto et al. ${ }^{16)}$ conducted fatigue tests of round bar specimens processed with equal channel angular pressing to clarify the effects of grain refinement on the growth behavior of small surface cracks. Qin et al. ${ }^{17)}$ investigated the effect of strain ranges on high temperature LCF of GH4742 superalloy and analyzed fatigue properties. Fleury and Rémy ${ }^{18)}$ conducted low cycle fatigue tests on AM1 nickel-base superalloy single crystals under axial strain control at 650,950 and $1100^{\circ} \mathrm{C}$. Sahu et al. ${ }^{19)}$ studied the effect of hot corrosion on low cycle fatigue behavior by conducting fatigue tests at $800^{\circ} \mathrm{C}$ in air on nickel-base superalloy SU 263. Turbine disks are subjected to high temperatures and effect of alternating loading, which are easy to produce strain-controlled high temperature LCF damage. Therefore, the investigation about the high temperature LCF behavior of the alloy is of great significance. Though many 
attempts have been done to investigate LCF behavior, no fatigue deformation mechanism in nickel-based superalloys was widely accepted. In this paper, the effects of strain amplitudes on fatigue behavior at $650^{\circ} \mathrm{C}$ were studied under the condition of total strain-controlled LCF. The temperature of $650^{\circ} \mathrm{C}$ is selected due to turbine disks designed to operate at about $650^{\circ} \mathrm{C}$ in current high performance aero-engine. LCF tests are always used to predict the deformation behavior and the fatigue life for hot-end components. Three fatigue life models were used to predict the fatigue life and evaluated for the LCF tests of the superalloy. The behavior and mechanisms of cyclic stress response were described and revealed, respectively. In order to reveal the mechanisms of fatigue fracture, the microstructures after fatigue tests were observed by SEM and TEM.

\section{Experimental Procedure}

\subsection{Material and heat treatments}

The alloy tested in the present study is a nickel-base wrought superalloy with a nominal chemical composition of Ni-14.0Cr-9.95Co-2.54Al-2.52Ti-5.12Mo-2.6Nb-0.06C (mass fraction, \%). The microstructure of the alloy consists of two major phases: $\gamma$ matrix with a face-centered cubic crystal structure and $\gamma^{\prime}$ strengthening precipitates with a cuboidal ordered $\mathrm{L}_{2}$ crystal structure. The volume fraction and the size of cuboidal $\gamma^{\prime}$ precipitates were $35 \%$ and about $300-400 \mathrm{~nm}$, respectively.

In order to improve the mechanical properties, eliminate residual stress and obtain proper microstructure of the alloy, the heat treatment is given as follows: the two step solution treatments at $1100^{\circ} \mathrm{C}$ for $8 \mathrm{~h}$ and $1000^{\circ} \mathrm{C}$ for $4 \mathrm{~h}$, and then the two step aging treatments at $775^{\circ} \mathrm{C}$ for $16 \mathrm{~h}$ and at $700^{\circ} \mathrm{C}$ for $16 \mathrm{~h}$. The specimens were cooled in air for every step heat treatment.

\subsection{Fatigue tests}

The standard of low cycle fatigue tests is referred to ISO 1099:2006 (Metallic materials-Fatigue testing-Axial-forcecontrolled method) ${ }^{20)}$ All the fatigue specimens with a gauge diameter $6.5 \mathrm{~mm}$, gauge length $16 \mathrm{~mm}$ and total length $90 \mathrm{~mm}$ tested in the present study were machined from a turbine disk in circumferential direction by wire-electrode cutting. The dimensions of the specimen are shown in Fig. 1.

The fatigue tests were performed on a MTS 810 fatigue testing machine in air at temperature of $650^{\circ} \mathrm{C}$. All the tests were conducted out under total axial strain-controlled from $0.3 \%$ to $0.7 \%$ with strain ratio of $R=-1$ and the loading frequency of $0.50 \mathrm{~Hz}$. A triangular waveform command signal was used during the fatigue tests. In order to monitor the cyclic hardening and softening behaviors, continuous records of the load-time and strain-time history were made throughout the fatigue tests. In addition, in order to monitor the stress change and the ability to absorb the irreversible deformation, hysteresis loops were also recorded regularly throughout the fatigue tests by computer. Strain was measured with a high temperature axial extensometer with a $16 \mathrm{~mm}$ gauge length.

After fatigue tests, the fracture surfaces and deformed microstructures was observed by Quanta 200FEG scanning

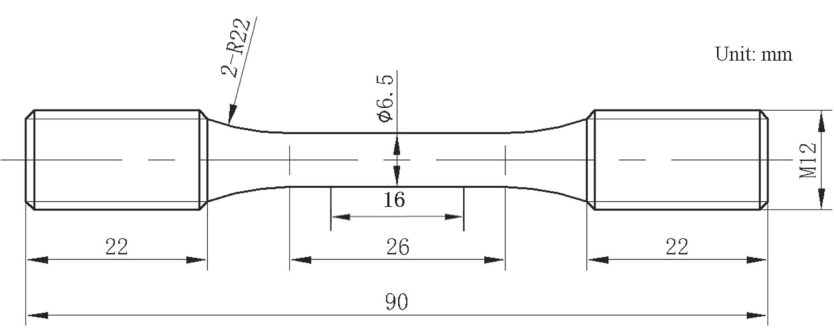

Fig. 1 The dimensions of the specimen.

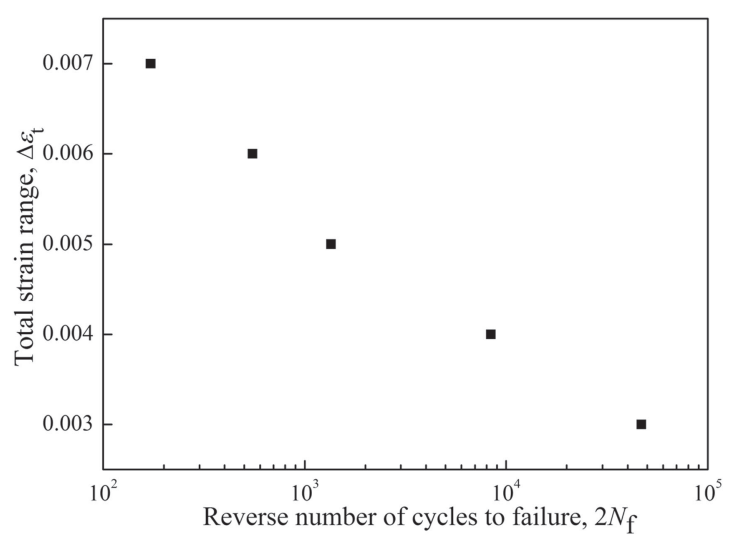

Fig. 2 The variation of total strain range with the reverse number of cycles to failure.

electron microscopy. To prepare thin foils for examination, they were sectioned perpendicular to the loading axis from the gauge section of fracture specimens. The samples were mechanically ground down to a thickness of approximately $50 \mu \mathrm{m}$ using $\mathrm{SiC}$ sandpaper and further thinned by twin-jet electrolytic thinning. Then dislocation characterizations and deformed microstructures were observed on Tecnai G2 F30 transmission electron microscopy.

\section{Results and Discussion}

\subsection{Fatigue life and life prediction model}

The relationship between the cyclic total strain range and the reverse number of cycles to failure under LCF conditions is plotted in Fig. 2. It can be observed that the number of cycles to failure significantly decreases with the increase of total strain range. As for total strain range of $0.3 \%$, the number of cycles to failure is approximately 272 times higher than that for total strain range of $0.7 \%$. It shows that the property at low strain amplitude is much better than that at high strain amplitude. Thus, the hot-end components are with a certain risk when they work under a condition of high alternating loading which induces high strain amplitude.

In numerous studies, LCF tests were carried out at variable temperatures, orientation, total strains, and cyclic frequency, which were frequently used to predict the deformation behavior and the fatigue life of hot-end components. In order to prevent the risk of sudden rupture, some accurate life prediction models for these hot-end components under LCF loading have been proposed over the past several decades. Manson-Coffin relationship, three-parameter power function relationship and Ostergren energy method are compared for the LCF life of the alloy. 


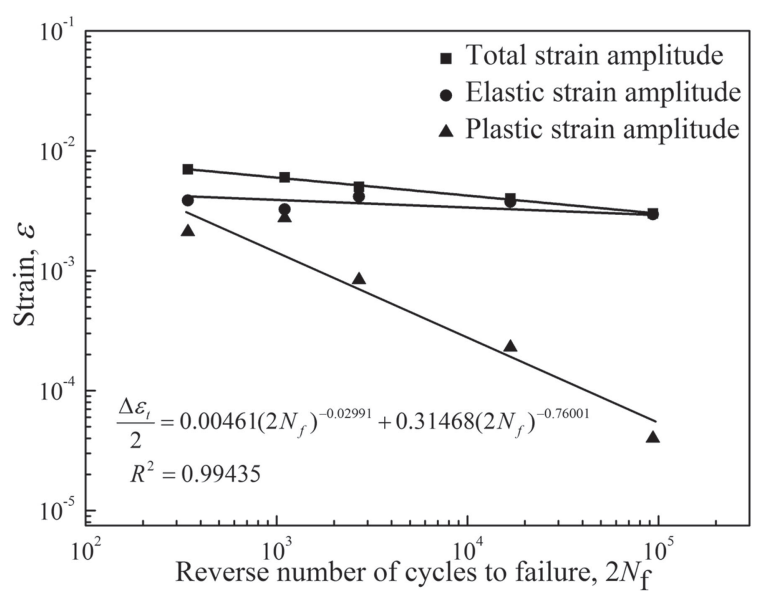

Fig. 3 The variation of the total, elastic and plastic amplitudes with the reverse number of cycles to failure.

\section{(1) Manson-Coffin relationship}

The Manson-Coffin relationship is used to describe the fatigue life of total strain-controlled LCF behavior. It is known to all, total strain can be divided into two parts: elastic strain and plastic strain. The relationship of the elastic, plastic and total strain ranges is expressed dependent on MansonCoffin relationship and Basqin relationship, ${ }^{21)}$ which is shown as follows:

$$
\frac{\Delta \varepsilon_{\mathrm{t}}}{2}=\frac{\Delta \varepsilon_{\mathrm{e}}}{2}+\frac{\Delta \varepsilon_{\mathrm{p}}}{2}=\frac{\sigma_{\mathrm{f}}^{\prime}}{E}\left(2 N_{\mathrm{f}}\right)^{b}+\varepsilon_{\mathrm{f}}^{\prime}\left(2 N_{\mathrm{f}}\right)^{c}
$$

Where $\Delta \varepsilon_{\mathrm{t}} / 2$ is the total strain amplitude; $\Delta \varepsilon_{\mathrm{e}} / 2$ is the elastic strain; $\Delta \varepsilon_{\mathrm{p}} / 2$ is the plastic strain; $2 N_{\mathrm{f}}$ is the number of cycles to fatigue; $\sigma_{\mathrm{f}}^{\prime}$ and $b$ are the fatigue strength coefficient and exponent, respectively; $\varepsilon_{\mathrm{f}}^{\prime}$ and $c$ are the fatigue ductility coefficient and exponent, respectively; $E$ is Young's modulus.

The relationships of the total strain, elastic and plastic amplitudes versus the number of cycles to failure are illustrated in Fig. 3. It can be seen that the plastic strain accounts for a small proportion in the total strain and its percentage increases with the increase of total strain amplitudes. It can be inferred that plastic deformation plays a critical role in the fatigue life of the alloy. The relationships of the elastic and plastic strain amplitudes versus number of cycles to failure were fitted according to eq. (1), which is also shown in Fig. 3. It can be observed that Mansion-Coffin relationship can fit the fatigue test data rather well. What is more, fatigue strength and ductility parameters dependent on LCF tests can be obtained. The corresponding MansonCoffin model is shown as follows:

$$
\frac{\Delta \varepsilon_{\mathrm{t}}}{2}=0.00461\left(2 N_{\mathrm{f}}\right)^{-0.02991}+0.31468\left(2 N_{\mathrm{f}}\right)^{-0.76001}
$$

\section{(2) Three-parameter power function}

The relationship of three-parameter power function can also be used to predict the fatigue life for strain-controlled LCF behavior. A significant advantage of three-parameter power function is that fatigue limits of alloys are considered in the relationship. The relationship of total strain range versus the number of cycles to failure is shown as follows: ${ }^{22}$

$$
N_{\mathrm{f}}\left(\Delta \varepsilon_{\mathrm{t}}-\Delta \varepsilon_{0}\right)^{m}=c
$$

Where $\Delta \varepsilon_{0}, m$ and $c$ are all material constants.

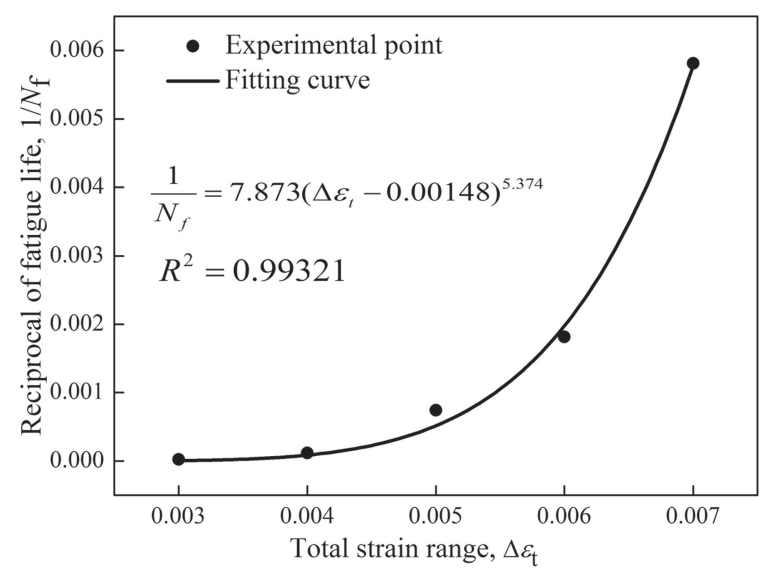

Fig. 4 The variation of cycles to failure with the total strain ranges.

The relationship of the number of cycles to failure versus the total strain ranges is depicted in Fig. 4. The relationship curve of the total strain ranges versus number of cycles to failure was fitted according to eq. (3). It can be seen that three-parameter power function has a perfect predicted effect of the fatigue life. The corresponding fatigue life model is shown as follows:

$$
N_{\mathrm{f}}=1.270 \times 10^{-10}\left(\Delta \varepsilon_{\mathrm{t}}-0.00148\right)^{-5.374}
$$

\section{(3) Ostergren energy method}

Ostergren $^{23)}$ proposed that low cycle fatigue damage is controlled by tensile hysteresis energy or strain energy. The relationship between hysteresis energy and fatigue life follows the exponential relationship, which is shown as follows:

$$
\Delta W \cdot N_{\mathrm{f}}{ }^{a}=c
$$

Where $\Delta W$ is tensile hysteresis energy; $a$ and $c$ are material constants.

The tensile hysteresis energy $\Delta W$ can be obtained as follows:

$$
\Delta W=\Delta \varepsilon_{\text {in }} \cdot \Delta \sigma_{\mathrm{t}}
$$

Where $\Delta \varepsilon_{\text {in }}$ is inelastic strain range, which can be replaced by $\Delta \varepsilon_{\mathrm{p}}$ during a pure fatigue; $\Delta \sigma_{\mathrm{t}}$ is tensile peak stress.

The relationship of the tensile hysteresis energy versus the number of cycles to failure is depicted in Fig. 5. The relationship curve of the tensile hysteresis energy versus the number of cycles to failure was fitted according to eq. (5). It can be observed that Ostergren energy method possesses a perfect predicted effect of the fatigue life. The corresponding fatigue life model is shown as follows:

$$
\Delta W \cdot N_{\mathrm{f}}^{1.135}=4705.88
$$

Above all, three classical life prediction models highly predict the fatigue life of the alloy. In order to make a comparison among these three classical life prediction models, experimental date and fitting date of $2 N_{\mathrm{f}}$ are illustrated in Fig. 6. The red line in Fig. 6 indicates the experimental data and fitting data of $2 N_{\mathrm{f}}$ are the same. The two black lines in Fig. 6 indicate 2-fold safety factor specified dispersing band. It presents perfect predicted effect when the fatigue life fitting data fall basically within 2-fold 


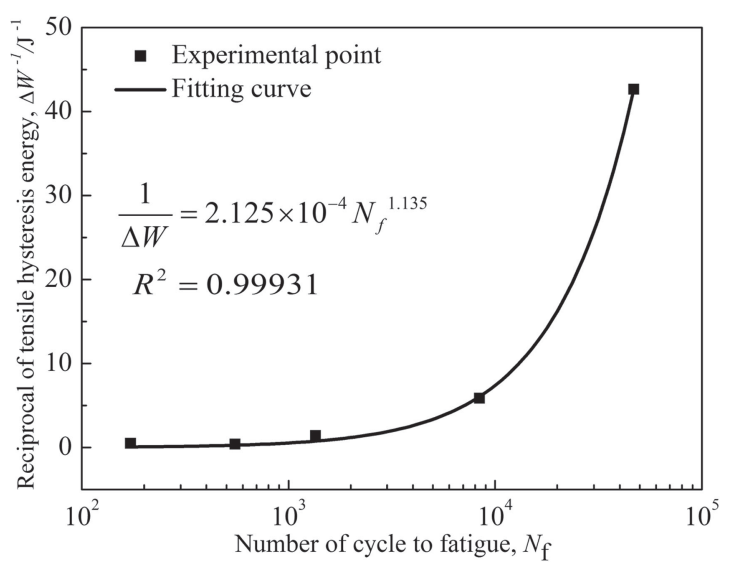

Fig. 5 The variation of the tensile hysteresis energy with the number of cycles to failure.

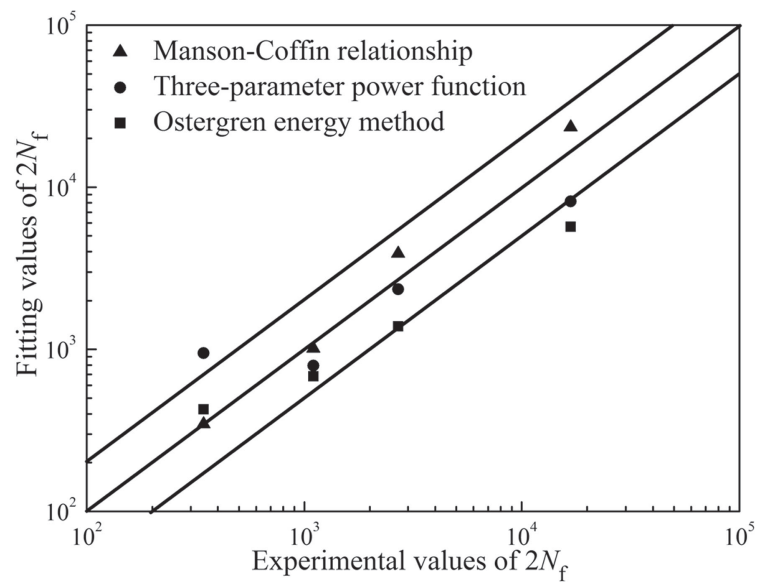

Fig. 6 The comparison of the predicted effect among three classical life prediction models.

safety factor specified dispersing band. It can be found that the prediction effect of Manson-Coffin relationship is better than that of three-parameter power function and Ostergren energy method due to the predicted date falling basically within two black lines for Manson-Coffin relationship. As for three-parameter power function relationship and Ostergren energy method, there is a data out of the two black lines. On the whole, the predicted effect is good during short fatigue life section and poor during long fatigue life section for Manson-Coffin relationship and Ostergren energy method. In contrast, the predicted effect is good during long fatigue life section and poor during short fatigue life section for threeparameter power function relationship. The relevance of experimental values and predicted values is used to evaluate the predicted effect of fatigue life model in the engineering.

\subsection{Cyclic stress response}

All the specimens were carried out under total straincontrolled condition. The constant changes of cyclic stress values with the number of cycles were recorded by computer at a given strain amplitude during the LCF process. Cyclic stress response macroscopically indicates cyclic deformation behavior of alloys under different loading conditions. The occurrence of cyclic deformation behavior is due to the changes of the microstructure for the alloys during LCF

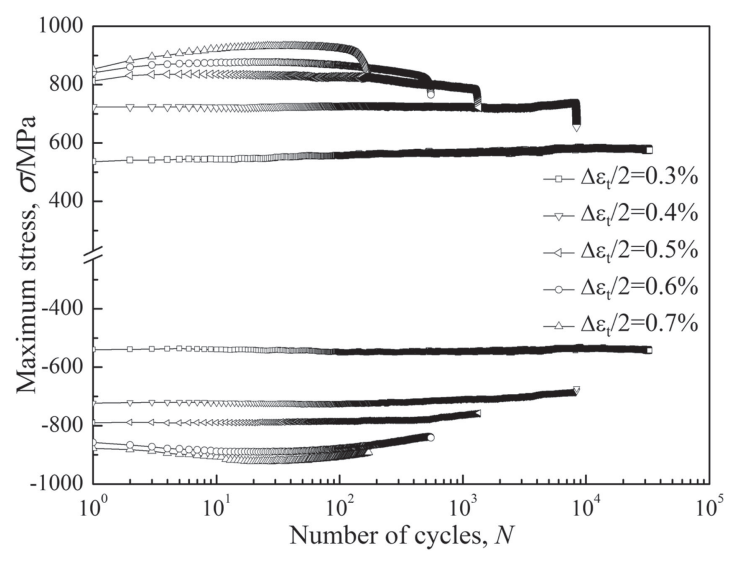

Fig. 7 Cyclic stress-life response of the alloy in the LCF tests.

tests. ${ }^{11)}$ Useful information can be obtained from cyclic stress response curve to understand the cyclic deformation behavior and the fatigue damage mechanisms. The maximum cyclic stress, including tensile stress and compressive stress, as a function of the number of cycles measured in LCF tests with different strain amplitudes is shown in Fig. 7. It can be seen from Fig. 7 that cyclic deformation behavior includes cyclic hardening and softening behaviors. It is obvious that stress amplitudes and fatigue lives are related with the total strain amplitudes.

As for cyclic tensile stress curve, it can be obtained that stress amplitudes increase with the increase of the total strain amplitudes. Large plastic deformation occurs due to high total strain amplitude, which results in numerous accumulation of dislocation pile-up. The accumulation of dislocation pile-up leads to the increase of stress amplitudes. What is more, the reduction of fatigue life is also been observed with the increase of total strain amplitudes. The cyclic hardening and softening behaviors can be seen at a given total strain amplitude during the LCF process. The cyclic hardening behavior occurs for all tested total strain amplitude. However, the continuous cycles and the degree of cyclic hardening behavior are much different among the total strain amplitudes from $0.3 \%$ to $0.7 \%$. At the total strain amplitude of $0.3 \%$, the superalloy exhibits a continuous cyclic hardening during the first 8000 cycles. At the total strain amplitude of $0.4 \%$, the superalloy exhibits a continuous cyclic hardening during the first 2000 cycles. At the total strain amplitude of $0.5 \%$, $0.6 \%$ and $0.7 \%$, the superalloy exhibits a continuous cyclic hardening during the first dozens of cycles. Therefore, it can come to the conclusion that the continuous cycles of cyclic hardening behavior decrease with the increase of total strain amplitudes. In addition, the degree of cyclic hardening behavior gradually increases with the increase of total strain amplitudes. It indicates that the superalloy is easier to reach the stress peak and to result in the reduction of fatigue life with the increase of total strain amplitudes. During the LCF tests, the softening behavior occurs after the cyclic hardening behavior. It can also come to the conclusion that the continuous cycles of cyclic softening behavior decrease with the increase of total strain amplitudes.

As for cyclic compressive stress curve, it can be obtained the same conclusion with cyclic tensile stress-life curve. 

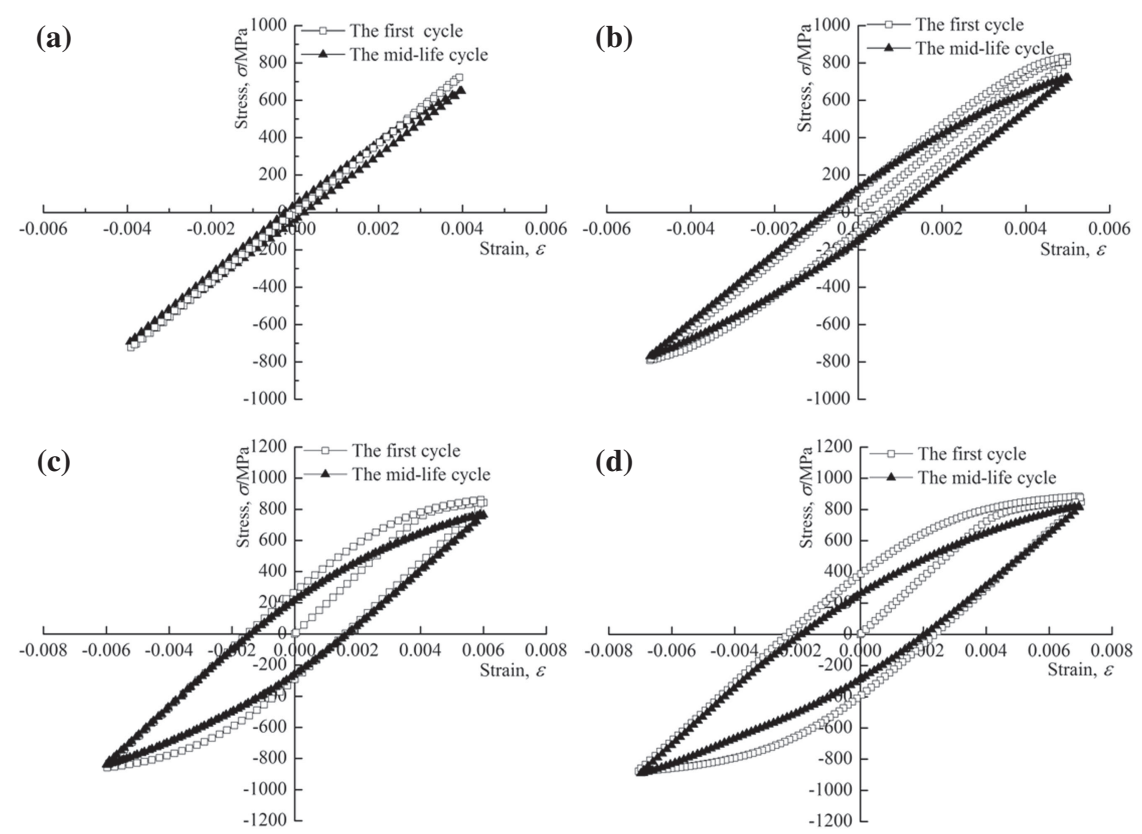

Fig. 8 The hysteresis loops of the alloy in the LCF tests; (a) $\Delta \varepsilon_{t} / 2=0.4 \%$, (b) $\Delta \varepsilon_{t} / 2=0.5 \%$, (c) $\Delta \varepsilon_{t} / 2=0.6 \%$, (d) $\Delta \varepsilon_{t} / 2=0.7 \%$.

However, it can be observed that stress amplitudes of final failure are different between the cyclic compressive stress curve and cyclic tensile stress curve. As for cyclic tensile stress curve, stress amplitudes are characterized by the rapid reduction as a result of the formation of macro crack and the subsequent crack propagation until failure before the final failure. The phenomenon does not occur in the cyclic compressive stress curve. It indicates that tensile stress is disadvantageous and dangerous for the superalloy during the fatigue loading.

\subsection{The hysteresis loops}

The hysteresis loops reflect continuous changes of stress and strain in the fatigue test. The shape of the hysteresis loop will change during the process of fatigue tests. For fatigue tests, after the initial maximum loading, the stress-strain response develops into a mechanical hysteresis loop when subjected to one loading cycle. The stress-strain relation tends to be stable gradually and then forms a stable hysteresis loop.

The hysteresis loops of the alloy in the LCF tests at total strain ranges from $0.4 \%$ to $0.7 \%$ are shown in Fig. 8 . The hysteresis loops are given by those at the first cycle $(N=1)$ and at the mid-life $\left(N=N_{\mathrm{f}} / 2\right.$, where $N_{\mathrm{f}}$ is the number of cycles to failure). It can be observed from Fig. 8 that the hysteresis loops shift downwards slightly with the increase of the number of cycles in the LCF tests. The downward shift of hysteresis loop is a characteristic of the LCF tests for the superalloy. The reduction of the maximum tensile stress at $650^{\circ} \mathrm{C}$ is frequently observed, which is due to stress relaxation at each cycle. The stress relaxation at elevated temperatures could be caused by two aspects. One is the weakened $\gamma / \gamma^{\prime}$ coherency. The other is plastic deformation by significant dislocation movements in $\gamma$ and $\gamma^{\prime}$ precipitates.

The cyclic strains play an important role in the deformation resistance. The change of the deformation resistance is related with the role of cyclic hardening and cyclic softening behaviors. The reduction of stress amplitude and the area of the hysteresis loop under constant strain amplitude indicate the occurrence of cyclic softening behavior. The increase of stress amplitude and the area of the hysteresis loop by constant strain amplitude show the occurrence of cyclic hardening behavior. It can be observed from Fig. 8 that the cyclic softening behavior occurs from first cycle to the midlife cycle. The area of hysteresis loops represents the ability to absorb the irreversible deformation energy. It can be seen that the area of hysteresis loops increases with the increase of strain amplitude, which indicates that the ability to absorb the irreversible deformation energy is higher and higher.

\subsection{Fracture behavior and fracture mechanism}

Fatigue fractographs of crack initiation and propagation were characterized on the fracture surfaces of fracture specimens by SEM. Typical fatigue fractographs consist of fatigue source region, crack propagation region and final instant rupture region. Fatigue source region, the largest brightness region of the fracture surface, is the initiation site of microcracks. Final instant rupture region, macroscopic characterized by fracture surface relatively rough, is formed by unstable propagation of fatigue cracks eventually.

The fracture morphologies of the superalloy after LCF at $650^{\circ} \mathrm{C}$ are shown in Fig. 9. At the total strain amplitude of $0.3 \%$, a large number of shallow dimples and rough fracture surface existed, which indicated the occurrence of plastic deformation of the superalloy during LCF process. A few spherical $\gamma^{\prime}$ precipitates occurred on the fracture surface. In addition, carbide fragment existed in some deep holes on fracture surface. At the total strain amplitude of $0.4 \%$, some cleavage-like stages could be observed on the fracture surface, which were composed of many cleavage planes. A large number of shallow dimples occurred. The fracture surface was relatively flat, with a small amount of spherical $\gamma^{\prime}$ precipitates dispersively distributed. At the total strain amplitude of $0.5 \%$, cracking hole gathered spherical $\gamma^{\prime}$ 


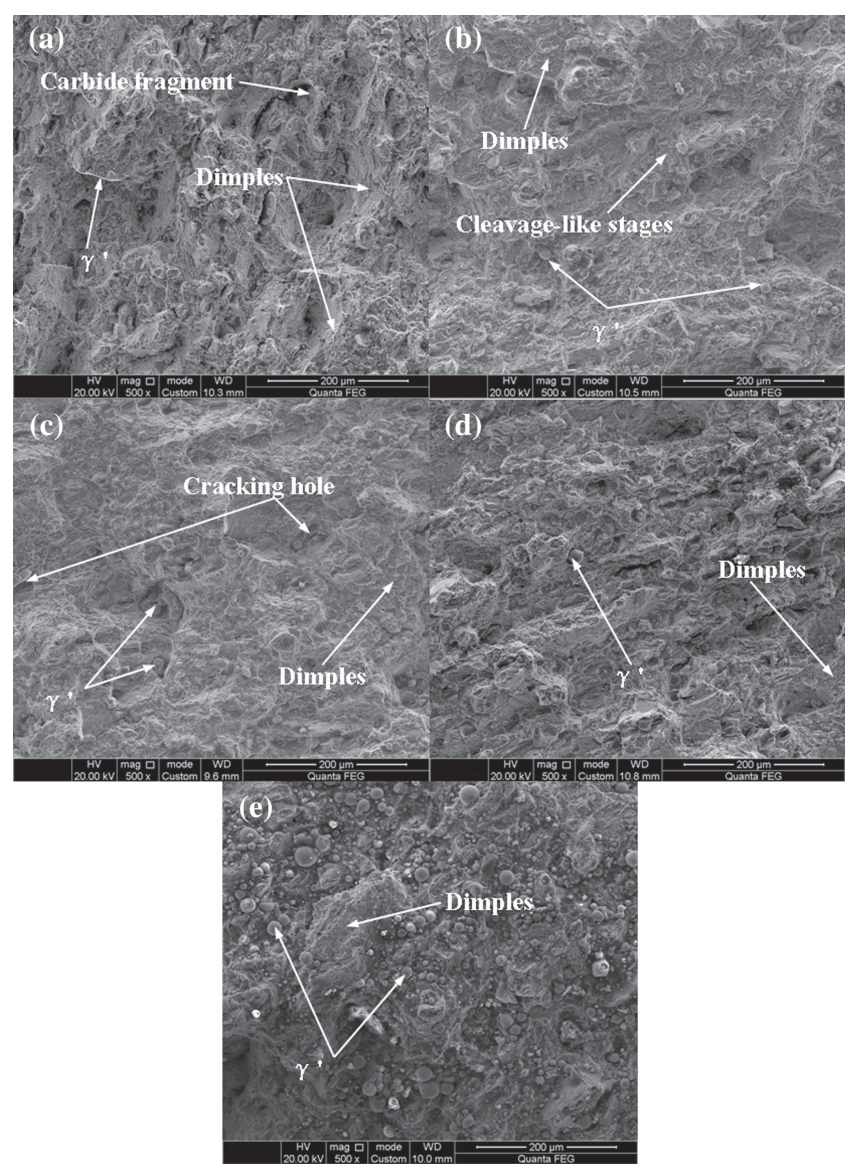

Fig. 9 The fracture morphologies of the superalloy after LCF at $650{ }^{\circ} \mathrm{C}$; (a) $\Delta \varepsilon_{\mathrm{t}} / 2=0.3 \%$, (b) $\Delta \varepsilon_{\mathrm{t}} / 2=0.4 \%$, (c) $\Delta \varepsilon_{\mathrm{t}} / 2=0.5 \%$, (d) $\Delta \varepsilon_{\mathrm{t}} / 2=$ $0.6 \%$, (e) $\Delta \varepsilon_{\mathrm{t}} / 2=0.7 \%$.

precipitates with different sizes. The spherical $\gamma^{\prime}$ precipitates accumulated at some areas. What is more, the intergranular cracking areas existed, where microcracks had not propagated due to the obstacle of the surrounding alloy structure. A small amount of cleavage-like stage existed on fracture surface. Some parallel small cracks appeared on the fracture surface. At the total strain amplitude of $0.6 \%$, numerous dimples occurred on fracture surface. The number of deep holes and spherical $\gamma^{\prime}$ precipitates increased. The size of spherical $\gamma^{\prime}$ precipitates differed obviously. A few carbide fragments existed in some deep pits on fracture surface. At the total strain amplitude of $0.7 \%$, the most striking feature was that fracture surface existed a large number of spherical $\gamma^{\prime}$ precipitates with different sizes.

The fatigue phenomenon can include three periods: 1) incubation period, characterized by cyclic hardening or softening behaviors; 2) microcrack initiation period, characterized by the appearance of measurable cracks; 3) crack propagation period, characterized by the growth of microcracks ultimately until the macroscopic failure. The incubation and initiation periods of microcracks accounts for a substantial portion of fatigue life. ${ }^{24)}$ McDowell $^{25)}$ proposed the variation in microstructure had a significant influence on the fatigue behavior for polycrystalline nickel-based superalloys. Yu et $a l .{ }^{26)}$ claimed that the fatigue failure mechanism was crack initiating along the slip bands that intersect the defects along the deformed zone and shearing decohesion while the pore induces a local stress concentration. Surface microcrack initiation is related with inclusions such as carbides, surface defects such as pits and notches, or stress concentration caused by machining. ${ }^{27,28)}$ Through above description about the fracture morphologies of the superalloy after LCF at $650^{\circ} \mathrm{C}$, it can be come to the conclusion that the combined effects of brittle fracture and ductile fracture determine the mechanism of fatigue fracture. The intergranular cracking, cleavage-like stages and carbide fragment represent the occurrence of brittle fracture. The numerous dimples on the specimen surface represent the occurrence of plastic deformation. Surface microcracks often initiate at grain boundaries due to strength weakening at high temperature and the carbide precipitates pile-up at grain boundary. The cracks initiate at multi-sites of free surface of the superalloy. Then cracks propagate in some way perpendicular to the applied loading until fracture.

\subsection{Dislocation structures and deformation mechanism}

In order to master the information about the deformation mechanisms of LCF for the superalloy, dislocation characterizations and deformed microstructures were observed. The TEM images of the deformation substructure after LCF tests are shown Fig. 10. It can be observed that the overall dislocation contents increase in the fatigued superalloy with the increase of total strain amplitudes. The deformation mode at this temperature consists of intense localized precipitates shearing.

At the total strain amplitude of $0.3 \%$, there were only a few dislocations with short and straight shape in $\gamma^{\prime}$ precipitates and at the interface of $\gamma^{\prime}$ precipitates and $\gamma$ matrix. The dislocations cut into the $\gamma^{\prime}$ precipitates. At the total strain amplitude of $0.4 \%$, the density of dislocations was relatively low. The dislocations were mainly restricted in the $\gamma$ matrix. The dislocation pile-up existed in some areas, which originated from multiple interactions between dislocations. What is more, a slip band formed in some region, which consisted of a large number of dislocations. At the total strain amplitude of $0.5 \%$, the number of slip band and dislocations were more than that at low total strain amplitude of $0.4 \%$. The dislocations mainly accumulated in the slip band. It can be clearly found that $\gamma^{\prime}$ precipitate was highly sheared due to cyclic plastic deformation on the slip plane. At the total strain amplitude of $0.6 \%$, it can be observed that the interaction between dislocations and $\gamma^{\prime}$ precipitates enhanced. Numerous dislocations distributed around $\gamma^{\prime}$ precipitates and some dislocations cut into $\gamma^{\prime}$ precipitates. The distribution of dislocations was uneven due to asymmetry in the deformation. At the total strain amplitude of $0.7 \%$, the number of dislocations substantially increased. Some dislocations cut into $\gamma^{\prime}$ precipitates and made them produce serious plastic deformation. Through analysis, it can draw the conclusion that the density of dislocations, the degree of dislocation pile-up, and the interaction between dislocations and $\gamma^{\prime}$ precipitates increase with the increase of total strain amplitudes.

As mentioned above, cyclic stress response includes cyclic hardening and softening behaviors. The deformation mechanism of cyclic stress response can be explained by the TEM images of the deformation substructure. The most commonly 


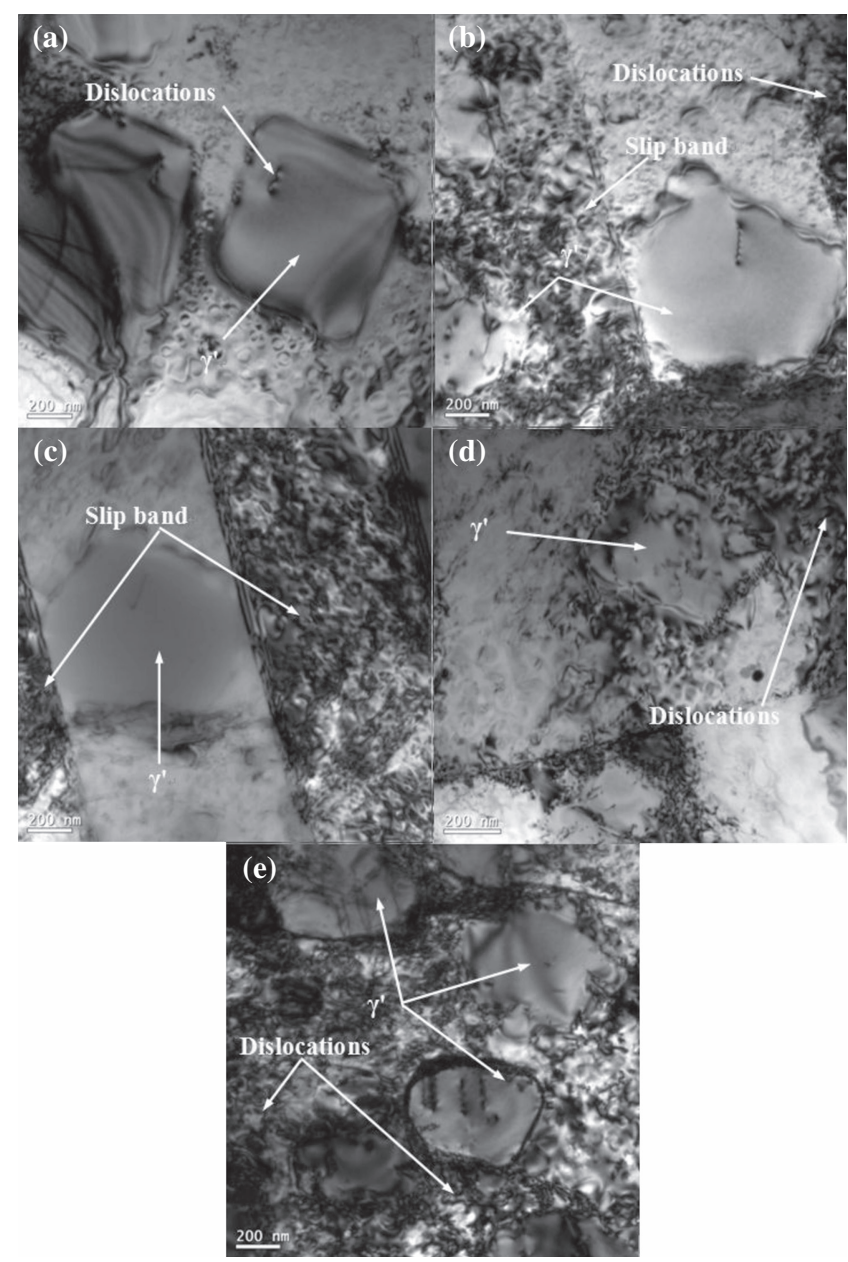

Fig. 10 The TEM images of the deformation substructure after LCF tests; (a) $\Delta \varepsilon_{\mathrm{t}} / 2=0.3 \%$, (b) $\Delta \varepsilon_{\mathrm{t}} / 2=0.4 \%$, (c) $\Delta \varepsilon_{\mathrm{t}} / 2=0.5 \%$, (d) $\Delta \varepsilon_{\mathrm{t}} / 2=$ $0.6 \%$, (e) $\Delta \varepsilon_{\mathrm{t}} / 2=0.7 \%$.

proposed mechanism of cyclic hardening phenomenon is the $\gamma^{\prime}$ precipitates hindering the moving of dislocations and the increase in the density of dislocations during deformation. Ovono et al. ${ }^{29)}$ claimed that the dislocations are going to assemble around $\theta^{\prime}$ semi-coherent precipitates and causing a hardening in the alloy. Calabresse et al. ${ }^{30)}$ attributed cyclic hardening to the dislocation interaction with the precipitates. The different distribution and density of dislocations hamper reciprocating motion of dislocations, which result in cyclic hardening behavior. Cyclic hardening behavior is also associated with the dislocation interactions or different degrees of the interaction between dislocation and $\gamma^{\prime}$ precipitates. Thus, the formation of dislocation network produces a certain obstacles for further movement of dislocations.

The cyclic softening behavior is attributed to the occurrence of misfit dislocations and some dislocations cutting into $\gamma^{\prime}$ precipitates, which was associated with the development of heterogeneous slip bands, formed as the precipitation hardening phase was repeatedly sheared by the action of dislocation cutting. This process must result in a stress relaxation and be related with the cyclic softening behavior. ${ }^{31,32)}$ The cyclic softening may be due to the loss of coherency due to coarsening of $\gamma^{\prime}$ precipitates. ${ }^{33,34)}$ The cyclic softening behavior is also related with the high temperature which is above $40 \%$ of the melting temperature of superalloys, therefore creep and relaxation and effects such as ageing of superalloys and instabilities of the precipitates can occur. ${ }^{35)}$ The cyclic softening behavior is attributed to a localization of plastic flow in slip bands. The cyclic softening is associated with the slip band or dislocations cutting orderly $\gamma^{\prime}$ precipitates and causing disorder. In this case, the strengthening effect of $\gamma^{\prime}$ precipitates is eliminated, thereby reducing the resistance of deformation of the materials.

Two kinds of interaction between dislocations and $\gamma^{\prime}$ precipitates can be observed. On the one hand, dislocations cut into the $\gamma^{\prime}$ precipitates. On the other hand, dislocations accumulate around the $\gamma^{\prime}$ precipitates. The dislocations at the boundaries of $\gamma / \gamma^{\prime}$ phases boundaries indicates that climbing mechanisms are active (Fig. 10(d)). When the interaction between dislocations and $\gamma^{\prime}$ precipitates increases to a certain extent, the breakdown of the $\gamma^{\prime}$ precipitates into smaller spherical shapes will occur (Fig. 10(e)). At lower strain levels, a few dislocations represent the occurrence of less plastic deformation. Dislocation accumulations are difficult to reach the critical value of stress concentration, which results in the delayed occurrence of fatigue microcracks. Therefore, the occurrence of fatigue microcracks requires a certain incubation period. In this case, the superalloy has long fatigue lives. However, a large number of dislocations indicate the occurrence of a large amount of plastic deformation for the superalloy at higher strain levels. A large number of dislocation accumulations are conducive to produce partial stress concentration, which easily causes the instability of corresponding parts when it is up to a certain extent and leads to the occurrence of cracks initiation. As the fatigue loading process to continue, it causes partial microcracks and fatigue fracture occurs ultimately. Therefore, the fatigue fracture of the alloy occurs in a short number of cycles. In this case, the superalloy has short fatigue lives. The partial stress concentration causes the instability of corresponding parts when it is up to a certain extent.

\section{Conclusion}

In this paper, the effects of strain amplitudes on fatigue behavior at $650^{\circ} \mathrm{C}$ were investigated under the condition of total strain-controlled LCF. Three fatigue life prediction models were evaluated for the LCF tests of the alloy. The fracture and deformation mechanisms were discussed in detail. The main results drawn from this study are as follows:

(1) The fatigue property at low strain amplitude is much better than that at high strain amplitude. Manson-Coffin relationship possesses a better prediction effect than that of three-parameter power function relationship and Ostergren energy method.

(2) Cyclic hardening behavior is associated with the different degrees of the interaction between dislocations and $\gamma^{\prime}$ precipitates. The cyclic softening is attributed to the slip band or dislocations cutting orderly $\gamma^{\prime}$ precipitates and causing disorder. The hysteresis loops shift downwards slightly with the increase of the number of cycles in the LCF tests. The reduction of the maximum tensile stress at $650^{\circ} \mathrm{C}$ at a given total strain is due to stress relaxation at each cycle. 
(3) The combined effects of brittle fracture and ductile fracture determine the fatigue fracture mechanism. The interaction between dislocations and $\gamma^{\prime}$ precipitates determine the deformation mechanism.

\section{Acknowledgments}

This study was financially supported by the National Natural Science Foundation of China (Grant No. 51575129, 51505101), Shandong Province Higher Educational Science and Technology Program (Grant No. J15LA51), China Postdoctoral Science Foundation (Grant No. 2015M571407).

\section{REFERENCES}

1) E. Fleury and L. Rémy: Metall. Mater. Trans. A 25 (1994) 99-109.

2) W. M. Guo, J. X. Dong and J. T. Wu: J. Iron. Steel Res. 17 (2005) 59 63.

3) Y. Itoh, M. Saitoh, K. Takaki and K. Fujiyama: Fatigue Fract. Eng. Mater. Struct. 24 (2001) 843-854.

4) Y. Liu, J. Yu, Y. Xu, X. F. Sun, H. R. Guan and Z. Q. Hu: Mater. Sci. Eng. A 454-455 (2007) 357-366.

5) G. F. Tian, C. C. Jia, J. T. Liu and B. F. Hu: Mater. Des. 30 (2009) 433 439.

6) A. Pineau and S. D. Antolovich: Eng. Failure Anal. 16 (2009) 26682697.

7) H. Mughrabi: Metall. Mater. Trans. B 40 (2009) 431-453.

8) J. Miao, T. M. Pollock and J. W. Jones: Acta Mater. 60 (2012) 2840 2854.

9) K. Obrtlík, M. Petrenec, J. Man, J. Polák and K. Hrbáček: J. Mater. Sci. 44 (2009) 3305-3314.

10) C. Stöcker, M. Zimmermann and H. J. Christ: Int. J. Fatigue 33 (2011) 2-9.

11) P. Zhang, Q. Zhu, C. Hu, C. J. Wang, G. Chen and H. Y. Qin: Mater. Des. 69 (2015) 12-21.

12) A. Shyam and W. W. Milligan: Acta Mater. 52 (2004) 1503-1513.

13) Y. L. Lu, L. Y. Chen, G. Y. Wang, L. Y. Chen, G. Y. Wang, M. L.
Benson, P. K. Liaw, S. A. Thompson, J. W. Blust, P. F. Browning, A. K. Bhattacharya, J. M. Aurrecoechea and D. L. Klarstrom: Mater. Sci. Eng. A 409 (2005) 282-291.

14) A. Bhattacharyya, G. V. S. Sastry and V. V. Kutumbarao: J. Mater. Sci. 34 (1999) 587-591.

15) M. Marchionni, G. A. Osinkolu and G. Onofrio: Int. J. Fatigue 24 (2002) 1261-1267.

16) M. Goto, K. Kamil, S. Z. Han, K. Euh, S. S. Kim and Y. Yokoho: Int. J. Fatigue 50 (2013) 63-71.

17) H. Y. Qin, G. Chen, Q. Zhu, C. J. Wang and P. Zhang: J. Iron Steel Res. Int. 22 (2015) 551-556.

18) E. Fleury and L. Rémy: Mater. Sci. Eng. A 167 (1993) 23-30.

19) J. K. Sahu, R. K. Gupta, J. Swaminathan, N. Paulose and S. L. Mannan: Int. J. Fatigue 51 (2013) 68-73.

20) ISO 1099:2006, Metallic materials-Fatigue testing-Axial-force-controlled method, Multiple, Distributed through American National Standards Inst., 2007.8.

21) D. C. Lord and L. F. Coffin: Metall. Trans. 4 (1973) 1647-1654.

22) H. M. Fu: Acta Aeronaut. Astronaut. Sin. 14 (1993) 173-176 (in Chinese).

23) W. J. Ostergren: J. Test. Eval. 4 (1976) 327-339.

24) S. Suresh and R. O. Ritchie: Int. Met. Rev. 29 (1984) 445-475.

25) D. L. McDowell: Mater. Sci. Eng. R 62 (2008) 67-123.

26) J. J. Yu, X. F. Sun, T. Jin, N. R. Zhao, H. R. Guan and Z. Q. Hu: Mater. Sci. Eng. A 527 (2010) 2379-2389.

27) K. S. Chan: Int. J. Fatigue 32 (2010) 1428-1447.

28) M. D. Sangid: Int. J. Fatigue 57 (2013) 58-72.

29) D. Ovono Ovono, I. Guillot and D. Massinon: J. Alloy. Comp. 452 (2008) 425-431.

30) C. Calabrese and C. Laird: Mater. Sci. Eng. A 13 (1974) 141-157.

31) J. X. Zhang, H. Harada, Y. Ro, Y. Koizumi and T. Kobayashi: Acta Mater. 56 (2008) 2975-2987.

32) S. K. Hwang, H. N. Lee and B. H. Yoon: Metall. Trans. A 20 (1989) 2793-2801.

33) H. Sehitoglu and D. A. Boismier: J. Eng. Mater. Tech. 5 (1990) 239254.

34) U. Glatzel and M. Feller-Kniepmeier: Scr. Metall. Mater. 25 (1991) 1845-1850.

35) B. Buchholz, H. Harders and U. Gampe: Mater. High Temp. 30 (2013) 43-48 